Pesquisa e Reflexão em Educação Básica

\title{
Quanto vale um pesquisador de juventudes no mercado oficial?
}

Rosane Maria de Castilho ${ }^{1}$

\begin{abstract}
Resumo:
A proposta deste texto é refletir sobre aspectos que impactam no trabalho dos pesquisadores, em especial, daqueles do campo das Juventudes: as inquietações, os desafios e as inúmeras interrogações que carregam quanto ao seu ofício e quanto ao seu valor no campo acadêmico. Para tanto, foram retomadas algumas experiências associadas ao percurso de pesquisa em níveis doutoral e pós-doutoral desta pesquisadora, levando-se em conta, tanto os aspectos ligados ao rigor científico, tais como o cuidado com a tessitura dos elementos associados à problemática de estudo, a acuidade quanto aos aspectos metodológicos è escolha dos instrumentos mais adequados para cada tipo ou modalidade de investigação, o compromisso quanto à análise e discussão dos resultados e as estratégias de devolução dos mesmos, quanto ao papel do pesquisador no que concerne ao seu compromisso político e, consequentemente, à sua emancipação intelectual, levando-se em conta as relações de poder, explícitas ou implícitas, que permeiam as relações no campo acadêmico.
\end{abstract}

\section{Palavras-chave:}

Juventudes. Pesquisa acadêmica. Papel do pesquisador. Emancipação intelectual.

\section{What's a youth researcher worth in the official market?}

\begin{abstract}
The purpose of this text is to debate about on aspects that impact the researcher's work: the concerns, the challenges and the numerous questions they carry about their craft and its value in the academic field. To this end, some experiences associated with the research path at the doctoral and postdoctoral levels of this researcher were resumed, taking into account both aspects related to scientific accuracy, such as the care with the structure of the elements associated with the study problem, the accuracy with regard to the methodological aspects and the choice of the most appropriate tools for each type, or modality, of research, the commitment regarding the analysis and discussion of the results and the return strategies of the, as to the role of researcher in what concerns their political commitment and, consequently, their intellectual emancipation, considering power relations, explicit or implicit, that permeate relationships in the academic field.
\end{abstract}

Keywords: Youth. Academic research. Role of researcher. Intellectual emancipation.

\footnotetext{
1 Doutora em Educação. Professora da Universidade Estadual de Goiás. E-mail: rosanecastilho.ueg@hotmail.com. ORCID iD: https://orcid.org/0000-0001-7862-7362.
} 


\section{¿Cuánto vale un investigador de juventudes em el mercado oficial?}

Resumen: La propuesta de este texto es reflexionar sobre aspectos que impactan el trabajo de los investigadores, especialmente de aquellos del campo de la juventud: las inquietudes, los desafíos y las innumerables interrogantes que cargan en cuanto a su oficio y en cuanto a su valor en el campo académico. Para ello, fueron retomadas algunas experiencias asociadas al recorrido de investigación en niveles doctoral y post-doctoral de esta investigadora, teniendo en cuenta tanto aspectos ligados al rigor científico, como el cuidado con la tesitura de los elementos asociados a la problemática de estudio, la agudeza en cuanto a los aspectos metodológicos y la elección de los instrumentos más adecuados para cada tipo, o modalidad de investigación, el compromisso con el análisis y la discusión de los resultados y las estrategias de devolución de los mismos, como al rol del investigador en lo que concierne a su compromiso político y, por consiguiente, a su emancipación intelectua, teniendo em cuenta las relaciones de poder, explícitas o implícitas, que permean las relaciones en el campo académico.

Palabras clave: Juventudes. Investigación académica. Rol del investigador. Emancipación intelectual.

O trabalho do pesquisador também é de fazer passar, por força de dados, de argumentos e da linguagem, um encoberto à condição de descoberto. Algo que estava aí, bem à frente de todos, revela-se de um golpe. É tudo? Claro que o pesquisador precisa ir muito além.

Juremir Machado da Silva

Esse texto busca ampliar a compreensão sobre aspectos que impactam o trabalho do pesquisador: dúvidas, inquietações e desafios que, de alguma forma, tangenciam as tantas interrogações que carregam quanto ao seu ofício e ao seu valor no campo acadêmico. Essa não é a primeira vez que proponho uma discussão sobre a temática. Também não é a primeira vez que relato as minhas vivências como pesquisadora. Os meus leitores deverão ter paciência e um tanto de esperança de que o percurso valha a pena.

Retomo o tema porque penso que as vivências compartilhadas podem auxiliar os jovens pesquisadores a compreender que entre o traçado de um projeto de pesquisa e sua realização, muitos "obstáculos" podem ocorrer, sendo necessário refletir sobre o emaranhado que constitui o cotidiano da operacionalização de um trabalho de campo, do qual não temos controle ou previsibilidade. Assim, como nos ensina Pais (2015), na obra Sociologia da vida quotidiana, é necessário ter em mente que a consciência epistemológica da impossibilidade de se abarcar o real em sua totalidade é "condição necessária" para alcançarmos os enigmas do cotidiano. E se as rotas cotidianas escapam às abstrações teóricas que se projetam sobre o real, há que se tecer novos arranjos, transgredir e subverter - com responsabilidade e compromisso - os panoramas já engendrados, buscando, em uma provável originalidade, novas possibilidades de aproximação, de interrogação e desvelamento do objeto em questão.

Adentrando ao tema, no que concerne aos aspectos formais do trabalho da pesquisa acadêmica, sempre insisti na tese de que, não obstante o compromisso com o rigor científico, não há como garantir a efetivação dos passos associados ao trajeto de investigação, na expectativa de que tudo flua como o pretendido. Isso porque a "obliquidade da vida" também se manifesta em nosso ofício de pesquisadores, cabendo a nós o compromisso com os sujeitos e com a proposta, enfrentando as dificuldades ao trabalho e, na medida do possível, abandonando a nossa vaidade profissional. Tarefa hercúlea para alguns, já que tendo a concordar com Weber (1970), que em seu texto Ciência como vocação, sustenta ser a vaidade passível de considerar-se uma "espécie de moléstia ocupacional" nos mundos acadêmico e erudito. 
Após essa breve digressão, retomo alguns aspectos acerca do ofício da pesquisa, sobre os quais já tratei anteriormente e que estão no cerne das discussões de pesquisadores e pesquisadoras do campo das Ciências Sociais e Humanas e mais especificamente, do campo da Educação: a necessidade do aprimoramento de seu traçado; o cuidado com a tessitura dos elementos associados à problemática de estudo; a acuidade quanto aos aspectos metodológicos; a escolha dos instrumentos mais adequados para cada tipo, ou modalidade, de investigação; as estratégias de devolução dos resultados (em especial à escola, lócus privilegiado de boa parte de nossos processos investigativos) e, fundamentalmente, a humildade diante da magnitude do que se descortina quando de sua realização.

Insisto em salientar que os elementos que envolvem a escrita de um projeto de pesquisa, e a posterior sistematização de seus dados, são facilmente encontrados e destrinchados em boas obras de metodologia do trabalho científico. Mas o cuidado e o respeito com o fazer acadêmico só se aprende com pesquisadores que reconhecem em seu trabalho as distintas possibilidades de se acercar ao objeto eleito, em seus diferentes contextos, circunstâncias e desafios, referenciando-o como um universo particular, prenhe de sentidos e significados que lhe são próprios e que garantem a sua singularidade e riqueza.

Quanto à operacionalização da pesquisa, inicialmente, cabe dizer que no trabalho associado ao meu percurso no doutorado, as dificuldades, tanto na aplicação do instrumento de coleta de dados (viés quantitativo), quanto na realização dos grupos focais (viés qualitativo) eram desafiadoras. Ora os "acordos" com a direção da instituição educativa falhavam e eu retornava à universidade de mãos vazias, ora ocorria algo que alterava a programação, que por sua vez alterava o cronograma daquela fase, gerando mudanças também nas fases posteriores.

Nessa trajetória, em uma das escolas pesquisadas no Brasil, no dia em que haveria uma sessão de grupo focal com alunos de uma determinada turma do segundo ano do ensino médio, um evento na escola alterou os planos: dois jovens foram pegos pelo vigia, fazendo sexo no estacionamento da instituição. Não será difícil imaginar o burburinho. Naquele contexto, não havia possibilidade de apresentar a proposta de pesquisa com os jovens do ensino médio. A proposta investigativa, diante do quadro que se descortinou na escola, era questão secundária para a instituição.

A fim de contribuir, propus à gestão da escola "aproveitar" os elementos associados ao fato ocorrido e propor um momento de reflexão com os alunos sobre os acordos que se podem produzir, com a anuência coletiva, para que um clima de convivência pacífica, quando não harmoniosa, se estabeleça em um espaço de aprendizagem, mas a sugestão não foi aceita. Apesar da preocupação com os prazos a cumprir, já que o meu retorno à Argentina já estava agendado, retornei "de mãos vazias" e com uma grande quantidade de novos questionamentos sobre os modelos de gestão que insistem em se estabelecer nas instituições de ensino em nosso país, em todos os níveis.

$\mathrm{Na}$ Argentina, em uma das escolas pesquisadas, no dia da aplicação do instrumento de coleta de dados em uma determinada turma, o pai de um aluno havia sido preso e retirado de casa, na presença da família, por uma suposta participação em um assalto. Os estudantes estavam muito mobilizados com a dor do colega, ainda em choque, e, em função do contexto, também não foi possível trabalhar, porém, nessa escola a perplexidade produziu frutos: a docente decidiu reunir o grupo em torno de uma "oficina" em que os alunos poderiam expressar a sua angústia escrevendo poesias - a aula de literatura tomaria um formato não previamente preparado, assim como a programação da pesquisa em questão. A relação entre o grupo se fortaleceu, permitindo, inclusive, o meu acolhimento quando da realização da atividade. Uma semana depois desse momento singular e rico em significados de ordem simbólica, retornei à escola e, assim, pude dar encaminhamento à programação concernente à pesquisa de campo.

Em Portugal, quando da realização do estágio pós-doutoral, a entrada nas escolas escolhidas para a realização da pesquisa foi uma odisseia. Em seu significado mais usual, considera-se este termo como associado a uma longa perambulação ou como um percurso marcado por inúmeros eventos imprevistos. Assim, o termo utilizado não é um exagero. Explico: a fim de pesquisar jovens 
estudantes da periferia, realizamos um traçado de estudo envolvendo a escolha de algumas escolas em bairros específicos de Lisboa. Trinta dias após a primeira tentativa de apresentar o projeto de investigação aos diretores das instituições escolares e, assim, obter a autorização para a aplicação da pesquisa de campo, eu ainda estava de mãos vazias. Não havia conseguido chegar aos diretores e não tinha perspectivas de alcançar sequer o passo inicial da investigação proposta.

Cheguei à reunião com o investigador-coordenador do estágio sem saber por onde começar. Discutimos possíveis saídas para o impasse e ele se propôs a entrar em contato com alguns diretores das escolas escolhidas e realizar uma prévia comunicação institucional. Depois de alguns contatos ineficazes, conseguimos agendar uma entrevista com a direção de uma das escolas cujo bairro não estava contido na prospecção inicial. Mas, nesse caso, o processo fluiu. Um segundo diretor, após vinte dias de insistentes solicitações, encaminhou o "meu caso" para a psicóloga da instituição, que gentilmente me atendeu. Em vista disso, a programação relativa ao trabalho de campo precisou ser refeita para que eu pudesse cumprir os prazos constantes no cronograma, previamente aprovado pelo comitê do Instituto de Ciências Sociais da Universidade de Lisboa.

$\mathrm{Na}$ Espanha, quando da minha primeira ida a Madrid, passei três dias visitando escolas públicas para realizar a pesquisa com estudantes secundaristas daquele país. O ayuntamiento escolhido para a realização da pesquisa de campo em Madrid foi eleito em função da similaridade com os bairros escolhidos em Goiânia e em Lisboa, no que tange à condição de classe dos moradores, à vulnerabilidade social vivenciada, entre outros critérios. Quando da "peregrinação", deixava toda a documentação relativa à pesquisa na secretaria das escolas: declaração de aceitação no pós-doutorado, parecer do investigador-coordenador do estágio/instituto que abrigou a pesquisa, um reduzido currículo pessoal, um contato telefônico e ainda um endereço de e-mail para comunicação. Ao fim do dia, uma constatação: as tentativas de um contato inicial para apresentação da proposta haviam sido infrutíferas.

Um dia, pela via de uma brasileira, cuja cunhada estava hospedada em um monastério do bairro escolhido para a pesquisa, fui apresentada a uma freira que já havia sido diretora de instituição escolar. Assim, consegui o contato com o diretor de uma escola conveniada entre a igreja católica e o poder público e pude realizar o trabalho. Apesar do "sopro de sorte", a proposta de aplicação da pesquisa em duas escolas não se concretizou plenamente naquele país. Um dos diretores de instituição escolar em Madrid, desculpou-se, alegando excesso de atividades escolares naquele semestre, além de um indicativo de greve, informando assim que não seria possível realizar as atividades propostas. Mais uma vez me vi convocada a enfrentar os obstáculos, não sem um tanto de desapontamento.

Considero importante salientar que, ao relatar as experiências frustradas com a gestão de algumas escolas, reconheço a alta carga de trabalho dos gestores escolares como um elemento a ser considerado. Muito já se escreveu sobre as condições de precariedade a que são submetidos os membros da comunidade educativa e não quero ser repetitiva, já que esse não é o objeto de nossa discussão aqui, embora considere importante manter em mente que a pesquisa acadêmica, quando realizada com o devido rigor e com o devido compromisso, não deve se distanciar dos aspectos políticos que integram o seu contexto, e que demandam uma postura crítica diante dele. Assim, como afirmou o docente argentino Roberto Follari (2011), uma postura habermasiana acerca da função do conhecimento sobre o real deve servir tanto como base ao autoentendimento, quanto como elemento de interpretação desse real que se desvela no cotidiano.

Após esse breve comentário, retomamos ao percurso da pesquisa: no Brasil, conheci um dedicado professor de Filosofia que me ajudou muito na aplicação dos instrumentos. Mas nosso "encontro" inicial não foi fácil: no terceiro dia da aplicação do questionário, fui levada pela coordenadora à sala em que o referido professor estava ministrando uma aula sobre "O legado grego para a civilização ocidental". O professor solicitou cinco minutos para finalizar a explanação sobre a temática. Percebi nele muito compromisso e amorosidade na relação com os alunos e, também, um grande arcabouço teórico para trabalhar a questão. Tocou-me a dedicação com que trabalhava 
o tema, mas percebi que ele estava um tanto incomodado com a minha presença. Mesmo assim, prontificou-se a ajudar no que fosse necessário.

Quando da aplicação do questionário, em uma dada questão que indagava sobre a opinião dos alunos acerca do valor (científico-social) do ensino formal oferecido pela escola, o docente se enfureceu. Pediu para interromper a aplicação dizendo que considerava "um desrespeito uma pesquisadora se propor a questionar a qualidade da escola" que abrigaria a pesquisa em curso. Fez uma enorme explanação sobre as precárias condições de trabalho docente, sobre a insuficiência das políticas públicas para a educação e convocou os alunos a ter muita "responsabilidade" na hora de responder. Convocou-os a "avaliar o contexto" antes de "dar uma resposta leviana". E um clima de perplexidade se instalou. Após a fala do docente, me manifestei dizendo que considerava importante a manifestação do professor, mas acreditava que as pesquisas sérias poderiam, efetivamente, viabilizar novos olhares sobre temas complexos e polêmicos como, por exemplo, o conceito de "qualidade" na educação. Ele concordou e assim pudemos prosseguir.

Na sala dos professores, após o ocorrido, conversamos longamente sobre a questão trazida por ele quando em sala de aula e ainda sobre o cuidado na construção dos instrumentos de coleta de dados para fins de pesquisa acadêmica. Descobrimos afinidades. Já engajado na proposta investigativa, o professor apresentou-me à equipe gestora de uma das escolas, localizada em um bairro periférico, para realizar a pesquisa. Parte do trabalho foi realizado lá. Não sem atropelos e imprevistos: desde a falta de luz na data da realização da roda de conversa (em função do furto de parte da fiação da escola na madrugada anterior) até uma blitz realizada pela polícia militar na porta da escola, o que gerou uma grande baixa na frequência de alunos do terceiro ano noturno, naquela semana. Na data, os alunos me relataram em conversa informal, que esse tipo de fiscalização policial sem aviso prévio ocorria com muita frequência no bairro, considerado rota do tráfico de drogas na cidade. Comentaram ainda que após essas "batidas" alguns colegas "desapareciam". Essa palavra ficou em minha cabeça. Para além de retornar em duas outras datas para efetivar a realização dos passos constantes no trabalho, me pus a pensar no que significa "desaparecer".

Confesso que ser pesquisadora do campo das Ciências Sociais e Humanas me traz um tanto de alívio, pois, em meu entendimento, a complexidade inerente aos aspectos associados à condição humana exige algo além do mero rigor científico para que seja desvelada. O rigor científico, ainda assim, é reconhecido em sua importância, embora não deva nos prender nas armadilhas das supostas "verdades objetivas".

Nesse diapasão, apesar dos constantes chamados ao objetivismo, que tende a desprezar o que não for passível do controle e da previsibilidade gerados por sofisticadas abstrações teóricas, penso que o pesquisador, ou quem se pretenda assumir com tal, deve lutar por sustentar sua condição de autonomia intelectual, embora o preço a pagar seja consideravelmente alto. Ao menos até que se alcance suficiente poder no campo, como nos orientou Bourdieu (1983), na obra Campo de poder, campo intelectual. Esse poder, fortemente presente nos campos de produção cultural, ocupou boa parte de seu trabalho investigativo sobre o sistema escolar francês e sobre a formação das elites intelectuais.

Importante frisar que, no trato com a pesquisa, não me proponho defender uma abordagem "espontaneísta". Muito ao contrário. Penso que a decisão de trilhar um percurso acadêmico seja um dado capaz, por si só, de sustentar o apreço pela magnitude do conhecimento produzido por sujeitos que reconhecem, na Academia, um fértil ambiente de produção e socialização de saberes.

Por outro lado, há que se considerar a magnitude da violência simbólica, adotada por "autoridades" que, encasteladas em suas poderosas associações e/ou instituições acadêmico-científicas e em nome de uma pretensa "excelência", se prestam a classificar o conhecimento produzido em determinados círculos acadêmicos como sendo de segunda categoria. O cinismo dessa postura, segundo a minha interpretação, ocorre porque essa cruenta taxonomia se dá com base em dados meramente quantitativos, cuja arbitrariedade essas ditas "autoridades" insistem em questionar, quando de seus discursos para "as massas" que lotam os eventos acadêmicos todos os anos. 
Assim, se a violência simbólica se exerce com a cumplicidade daqueles que a sofrem e também, com a colaboração daqueles que a exercem na medida em que não são conscientes de exercer ou sofrer seus impactos - sobre a temática, Bourdieu (2014), em sua obra Sobre o Estado, muito nos esclarece - há que se pensar nos elementos que envolvem esse processo, criando condições para refletir amplamente sobre essas "formas de coerção", que banalizam e corroem as relações nos mais diferentes níveis da vida acadêmica. A quantidade de alunos da pós-graduação que fazem uso de medicação psiquiátrica para "suportar a pressão" de seus processos de mestrado e doutorado, já foi objeto de discussão em inúmeros congressos científicos.

Tal violência, como modus operandi da Academia, é uma das formas de coerção que impera no campo científico, para desespero daqueles que lutam contra o processo de reificação, de coisificação dos sujeitos, e até mesmo de "precificação dos produtos" gerados em âmbito acadêmico. Sobre a pretensa legitimidade dos critérios acadêmico-científicos adotados nas avaliações de mérito, Adorno (1995), no texto "A filosofia e os professores", muito pode contribuir em nossas reflexões.

Enfim, após um percurso de reflexões, cabe a pergunta: quanto vale um pesquisador de juventudes no mercado oficial? E a resposta imediata estará atrelada ao status da instituição e dos grupos de elite aos quais o mesmo se vincula, pela via da chancela que sustenta o seu poder ou determina a sua "subalternidade" no campo acadêmico.

Por outro lado, não obstante as agruras enfrentadas, penso que pesquisar é constituir novas rotas de descobrimento, tendo por fundamento tanto a bússola dos saberes já divisados quanto a respeitosa curiosidade diante de um novo mundo que se descortina. Assim, no afã de sustentar um tanto da necessária emancipação, poderemos nos associar a quem, como nós, encontra sentido e significado em seu ofício.

Quanto valemos? Ninguém além de nós pode, senão pela via de uma honesta análise de nossos propósitos, precisar. Quanto ao mercado oficial, sabemos, minimamente, quais os critérios para se ocupar as cadeiras do poder. Isso deveria nos deixar aliviados por não estarmos lá.

\section{Referências}

ADORNO, Theodor W. Educação e emancipação. São Paulo: Paz e Terra, 1995.

BOURDIEU, Pierre. Campo de poder, campo intelectual. Buenos Aires: Folios, 1983.

BOURDIEU, Pierre. Sobre o Estado. São Paulo: Companhia das Letras, 2014.

FOLLARI, Roberto A. Para quem investigamos e escrevemos? Para além de populistas e elitistas. In: GARCIA, Regina Leite (org.). Para quem pesquisamos e para quem escrevemos: o impasse dos intelectuais. São Paulo: Cortez, 2011. p. 43-69.

PAIS, José Machado. Sociologia da vida quotidiana. Lisboa: Imprensa de Ciências Sociais, 2015.

SILVA, Juremir Machado da. O que pesquisar quer dizer: como fazer textos acadêmicos sem medo da ABNT e da CAPES. 2. ed. Porto Alegre: Sulina, 2011.

WEBER, Max. Ciência como vocação. In: WEBER, Max. Ciência e política: duas vocações. São Paulo: Cultrix, 1970. p. 17-52.

Data de submissão: 04/01/2021

Data de aceite: 05/01/2021 